tive changes in the lateral region of the cord were evidently due to a sclerosis produced by the extension inwards of inflammatory changes beginning in the pia mater. As mentioned above, they affected the peripheral region of the cord, and also implicated the crossed pyramidal tract. In the lumbar region, however, there was distinct secondary descending sclerosis, exactly limited to the crossed pyramidal tract.

A prominent feature of the pathological changes was the endarteritis of the larger vessels, especially in the meninges and the hyaline degeneration of the smaller vessels. All the degenerated portions of the cord presented sclerotic changes except those in the posterior columns in the lowest dorsal region, and at one point in the antero-lateral columns on the right side in the upper dorsal region. Here the changes were those of a gummatous infiltration.

The pathological changes were certainly not those of disseminated sclerosis; their distribution was not sufficiently irregular; there was also marked secondary ascending sclerosis in the cervical region, which is very rare in disseminated sclerosis; and during life the symptoms were not those of the disease just mentioned. The typical endarteritis, the slight meningeal changes, the extension of the lesion from the meninges into the adjacent parts of the cord, the histological (gummatous) nature of the most recent patches, and the syphilitic history of the patient, all indicate clearly that the case was one of spinal syphilis.

The pathological and microscopical examinations of the spinal cord, which have hitherto been recorded in cases of Erb's syphilitic spinal paralysis, are too few to enable one to draw definite conclusions as to the lesions, and possibly they may not always be of the same nature and distribution. But the above record furnishes a good example of the changes which may be met with, in a case which presented during life most of the symptoms of "Erb's syphilitic spinal paralysis." The chief point of difference from Erb's cases was the gait; there was considerable inco-ordination in the movements of the legs; but this has been recorded in other cases also.

Briefly the pathological changes may be summarised as follows: Endarteritis and hyaline degeneration of the arteries of the spinal cord and meninges; slight meningitis ; gummatous infiltration of the right antero-lateral columns in the upper dorsal region; sclerosis of the periphery of the cord in the lateral columns in the whole of the dorsal region; selerosis in the posterior median columns in the upper dorsal region; irregular sclerotic patches, with one patch of cell infiltration (gummatous) in the lowest dorsal region ; descending sclerosis in the lumbar crossed pyramidal tracts; ascending sclerosis in the cervical posterior median columns.

1 Erb: Neurologisches Centralblatt, No. $6,1892.2$ Oppenheim : Berl. klin. Woch, No. 35, 1893. 3 Clark, M. : Lancet, vol. i, 1894. 4 Turner : Lancet, vol. i, 189.- 5 Kuh : Deutsches Zeitschrift f. Nervenheilkunde, 1893, Band 3. logisches Centralblatt, No. 12, 1893 .

\section{A CASE OF SYRINGOMYELIA.}

By JAMES CARSLAW, M.A., M.B., C.M., Assistant to Professor of Medicine, Glasgow University ; Extra Dispensary
Physician, Western Infirmary, Glasgow.

IT is only within the last few years that the possibility of giving a clinical picture of syringomyelia has been recognised. The presence of abnormal cavities in the spinal cord was first recorded by Morgagni ${ }^{1}$ nearly two centuries ago, and these for long were looked upon as mere pathological curiosities. In later years, however, the pathology of this condition has been pretty clearly established, and now syringomyelia is recognised as having a definite symptomatology, and the striking statement is made by Starr ${ }^{2}$ that "it is not less common than such a well-known disease as disseminated sclerosis," and Charcot agreed with Schultze that "it was at least as common as amyotrophic lateral sclerosis." 3 The rapidity with which this adyance has been made in our knowledge of the disease is strikingly brought out by comparing the wellestablished group of symptoms now regarded as diagnostic, and described in detail by Bruhl, ${ }^{4}$ with the statement made by Erb, even in 1878, that "all experience thus far teaches that

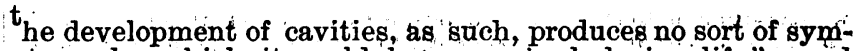
ptoms by which it could be recognised during life"; and again, that " no special symptom, no peculiarity in the course of the disease. betrays the complication." The following case is instructive, especially as it illustrates some of the variations from the classical type that may be met with, and I have Sir William T. Gairdner's kind permission to publish it in detail :

J. B., aged 33, a farm servant, was admitted to Sir William' Gairdner's wardin the Glasgow Western Infirmary on February 9 th, 1898 , suffering fropm a chronic nervous illness, the most prominent features of which were some sensory disturbance.

History. - As a child he was healthy, the only illness he remembers having had being measles. He had no convulsions, but at the age of ro he says he was nervous and easily frightened, though not prevented from attending school. At the age of 12 he left school and began to work on a
farm, and two years later, during a severe winter, he suffered much from farm, and two years later, during a severe winter, he suffered much from
fissures on his hands, which were long in healing and more troublesome fissures on his hands, which were long in healing and more troublesome
on the right hand. From this time the right hand was noticed to be weak, on the right hand. From this time the right hand was noticed to be weak,
and he began in his work to use the left hand more than the right. Durand he began in his work to use the left hand more than the right. During the following winters he suffered much from chilblains on his hands on the ring finger of the right hand, which took a long time to heal. . The on the ring finger of the right hand, which took a long time to heal.. The the muscles were becoming atrophied. In July, r88, he suffered the muscles were becoming atrophied. In July, r883, he sufered digestion with occasional vomiting, and a gnawing pain in dige back between the shoulders. He went on with his work till towards the end of the month, when for a few days the headache was very severe, and he could not bear the light on his eyes, and was sleepless. One day at this time, when walking in the garden, he suddenly got dizzy and fell, but without hurt or loss of consciousness, and he was able to get up and walk into the house. Next morning he fell down in the house, and had to be lifted into bed, a movement of which he was quite unconscious. He remembers being out of bed again by the time the doctor arrived, and
also that he was out of bed a day or two later, having his head shaved and also that he was out of bed a day or two later, having his head shaved and a blister applied. However, within a week he was completely paralysed. move arms, legs, or back, but gradually recovery took place, more in arms and back than in legs, so that he was soon able to get out of bed, and walk with the aid of sticks. It should be added that he suffered from retention of urine during the first fortnight he was confined to bed, but after that there were urinary difficulties, though never complete retention. After this headache was occasional, and he often felt a sharp pain in the right occipital region, but he practically suffered no pain apart from this headache. He came to the Western Infirmary in July, . 1884, and remained under treatment for about five months. His case at this time was indexed "spastic paraplegia," there being noted in addition some permanent inequality of the pupils, atrophy and weakness of the right arm, and some sensory disturbance. Very little change took place during his residence, and soon after leaving he proceeded to the University College Hospital, London, where he was under the care of Sir William Gowers. Since then his general condition has not changed much. He has not been able to do any regular work. His right arm has gradually been getting more wasted and weaker, and latterly there have been some subjective sensory disturbances in the left hand, which is getting more susceptible to cold, and of the lower limbs and the urinary difficulties have remained much the of the lower limbs and the urinary difficulties have remained much the Fame. In August, 1897, the patient was in the Glasgow Royal Infirmary. Family History.- His parents are both dead, the rather at age of 67, after an attack of paralysis of the right side; the mother at the age of 66 , from influenza with pulmonary complications. He is one of a family of three sons, his two brothers being alive
suffered from any nervous illness. Present State. - The patient is a healthy-looking man. There is some codema
of the feet and legs. There is slight postero-lateral curvature of the spipe of the feet and legs. There isslight postero-lateral curvature of the spipe in the upper dorsal region, the convexity being to the right. There is a difference in the power of the facial muscles can be appreciated. There is. difference in the power of the facial muscles can be appreciated. There is marked paresis of the right arm, especially of the hand, but the grasp of the left hand is probaby also deficient. With the dynamometer the grasp of the right hand is registered as ro, and that of the left as 45 . There is considerable atrophy of the right hand and forearm as compared with the left. The thenar and hypothenar eminences are praetically gone, and the interossei muscles very deficient, There is characteristic deficiency in the movements of the hand. He cannot oppose the thumb to any of the fingers, and when he tries to fully extend the fingers there is over-extension of the first phalanges and flexion of the terminal ones. There is distinct though less marked wasting of the thenar and hypothenar eminences of the left hand, and this is associated with an inability to oppose the left thumb to the little finger. No relative wasting is made out in the shoulder muscles. Fibrillary tremor is present in the muscles of both hands. There is no rigidity of the upper limbs, though there is some tendency to contraction of the third, fourth, and fifth fingers of the right hand. No triceps, biceps, or wrist jerks are got on either arm. There is paresie of both legs, slightly more marked on the right side. Secondary rigidity is very marked, and the attitude of the limbs characteristic. The feet are extended at the ankles, and the. first phalanges of the toes are over-extended, while the terminal phalanges are fully flexed. The great toes are specially affected in this way, that of the left foot being quite dislocated at the metatarso-phalangeal joint. The muscles of the right leg seem to be less bulky than those of the left, and at the thickest part of the calf, though the circumferential measurement varies to some extent wit

to one inch less than the left.

The knee-jerks and ankle clonus are exaggerated on both sides, and the plantar reflexes are very distinct. The exigastric, abdominal, and cremasteric reflexes are not got. There are no tremors of the limbs.

There is no evidence of trophic change in the skin or its appendagels 
The semation of touch seems to be perfectly normal all over the body and an examination of the face, arms, and legs with thie æsthesiometer (Wober's) reveals no appreciable difference in the two sides of the'body. The.locasisation of touch is very qeourrate, and no delay in the transmissian of the sensation can be apprectated. However sensation of pain and thermal sensation appear to be somewhat defectlve all over the body, the deficiency being most marked in the right arm, less in the left arm, and least in the legs; trunk, and face. The distribution of the loss of sensation of pain and that of the loss of sensation of heat and cold correspond pretty well; though the former is rather more profound. In testin the sensation of pain with a sharp needle, it is found that the needle can be passed right through the skin of the arms, and even of the legs and of the fropt of the chest, without complaint, and there is great diffeulty dietropt or chest, without complaint, and there is great difficulty in tip of one's finger. - The analgesia varies in degree at different areas, being most profound in the right arm and shoulder from the neck, less in the left arm from the shoulder girdle, and least marked elsewhere. The thermo-anæsthesia is greatest in the right arm from the shoulder girdle, less in the right side' of the neck and the left arm from the shoulder girdle, but fairly good in the front of chest and

The skin is very insensitive to electrical stimulation. In the muscles of The skin is very insensitive to electrical stimulation. In the muscles of both arms and hands the galvanic current produces contractions with 2 to 3 milliamperes. there being considelable difficulty in getting responses I milliampere is required. With the faradic electricity, the muscles of the arms and hands contract with a coil distance of 5 or $6 \mathrm{~cm}$., while for the face the coil distance is $7 \mathrm{~cm}$. In the legs muscular contractions are only produced by comparatively strong currents, both galvanic and faradic. There is no qualitative change, $\mathbf{K}$.C.C. always being greater than or equal There is

to A.C.C.

When he walks the patient keeps his feet rather far apart; his limbs are stiff, and he swings round both feet, trailing the balls of the toes on the ground. His gait is rather spastic than ataxic, but he cannot walk so well in the dark, and he cannot stand steadily with his feet together and his eyes shut. Except for occasional headache he makes no complain of pain, either in back, round the trunk, or in the limbs: He has no
speech defect, and his intellectual capacity is unaltered and his memory

speod.

In regard to the eyes, it is noted that the pupils are unequal, the righ always smaller than the left. Both pupils respond, however, to light and on accommodation. There is at times slight nystagmus. There is no odulo-motor paralysis, though there is slight convergent strabismus. Th visual acuteness is normal, as also the sense of colour and the field of vision. The fundus oculi reveals nothing of special note. There is probably diminution of the sexual sense, though it is not lost. There is no alteration of the other special senses.

The patient's temperature is normal. His appetite is good, and, excep for some flatulent distension after food, his digestive system is healthy. The lungs and heart are normal. The urine is slightly alkaline, usually albumen.

No alteration took place in the patient's condition during residence in hospital, and he was dismissed on April rst, 1898 .

In this case all the symptoms that one looks for in syringomyelia are present, though their distribution and their relative prominence differ considerably from the usual type. There are symptoms indicating some lesion of the anterior cornua, namely, the advancing muscular atrophy of the hands and arms, especially the right. There are also symptoms pointing to lesions of the posterior cornua, namely, the losis of sensation of pain, and of heat and cold, with the preservation of the sense of touch and the muscle sense. No trophic changes are present in addition to the wasting of the muscles, unless the chilblains and the occurrence of a whitlow are of that significance. But there are present characteristic disturbances of the eyes, most notably the disparity of the pupils, indicating the implication of the sympathetic fibres from the'spinal cord for the eye; also curvature of the vertebral column, and some urinary difficulties. In addition there are symptoms which point to extension of the lesion to the white substance of the cord, by pressure or otherwise, and consequent , secondary degeneration. Implication of the lateral tracts is indicated very distinctly in this case by the spastic paraplegia. Slight degeneration of the posterior columns is suggested by the small amount of ataxia that is present (Romberg's. sign). The level of the primary lesion is indicated by the distribution of the muscular atrophy and by the pupillary sign, both of which were present early.

In the diagnosis of syringomyelia it is the sensory phenomena that are most important, as distinguishing it from other nervous diseases. This patient's present condition resembles in many ways amyotrophic lateral sclerosis, although the muscular atrophy is decidedly asymmetrical, and the spastic paraplegia is rather out of proportion to the atrophy. However, there is clearly something more than amyotrophic lateral sclerosis, and the ocular symptoms, the sensory phenomena, and the onset of the disease in early youth all point to' a 'different diagnosis.' Similarly simple progressive musculair atrophy is distinguished from syringomyelia by the absence of [sẹnsory disturbances in the former; $:$ and dissemingted sclerosis would be distinguished by the presence of affections of the speech, characteristic tremors, and, as a : rule, normal sensibility. Again, peripheral neuritis may be differentiated as a rule with ease, for though its prominent symptoms are altered sensations, the tactile sensation is what is invariably most affected, and there is never present the dissociation of the different forms of sensation. Moreover, the anæsthesia of neuritis corresponds .with the distribution of the affected nerves, whereas the sensory phenomena of syringomyelia are present in regular defined segments.

Another disease which must be distinguished is hysteria, and Charcot has pointed out that the sensory phenomena so characteristic of syringomyelia may be met with in hysteria. One of the points to be observed in making a differential diagnosis is that disturbances of the special senses are absent in syringomyelia, though they are common in hysteria, the most common being diminution of the visual field. Moreover, in hysteria the paralytic phenomena are usually rapid in their onset, while in syringomyelia the onset is slow and progressive. In hysteria also there is sometimes equally sudden disappearance of the symptoms; it may be with recurrence brought about by emotional causes, but such sudden changes are unknown in syringomyelia. . Our present patient was particularly free from any disposition to hysteria, and the differential diagnosis was not difficult.

The course of this patient's illness has been rather anomalous. It seems to have begun at the age of 14 with progressive atrophy of the muscles of the right hand. This made.slow but -steady progress, and has latterly affected also the left hand. But suddenly, at the age of 18 , he took a "fit" associated with unconsciousness, and followed by complete paraplegia, from which a large amount of recovery was got. The most probable explanation of such an unusual mode of development is the occurrence of spinal hæmorrhage. The now generally-recognised cause of syringomyelia is gliomatosis of the cord; and it has been pointed out that certain gliomata are very vascular, and may be affected by hæmorrhage. The sudden pressure would be the cause of the apoplectiform seizure and the succeeding paraplegia, while the partial recovery is explained by the reabsorption of the hæmorrhage. Syringomyelia is essentially a chronic illness, and though such sudden seizures are often regarded-at least by the patient-as the onset of the illness, careful: inquiry will show, as in this case, that the onset of the disease was antecedent to the sudden attack, there having been some previous progressive atrophy of muscles or some sensory manifestations. Indeed, the chronicity of the disease is well illustrated by this case, as there is comparatively little change in his condition since his former residence in the Western Infirmary, now fourteen years ago.

It is of considerable interest to look back on the report of this patient's condition on his first admission in $1884^{\circ}$ At that time the case was regarded as prominently one of spastic : paraplegia, though this diagnosis does not seem to have been regarded as quite complete, and the inequality of the pupils, the atrophy of the right hand, and some not very clearly-defined sensory irregularities. were the disturbing elements. However, it was just about this time that syringomyelia was beginning to be considered to be a disease with definite symptoms, and capable of clinical diagnosis. The publications of Schultze $^{6}$ and Kahler, ${ }^{7}$ commencing in $\mathbf{1 8 8 2}$, first drew attention to these symptoms, and in particular to the typical sensory phenomena which Charcot called the "dissociation syringomyélique." Subsequent clinical observations, frequently verified post mortem, have fully confirmed the importance of their work, and especially the importance of systematic examination of sensation in its different phases. From the numerous cases since reported, in some of which previous diagnosis of progressive muscular atrophy, spastic paraplegia, or amyotrophic lateral sclerosis had been made, it now appears that this "dissociation syringomyélique" is far from being such a rare eondition as used to be thought.

Another point of interest in this case is the widespread distribution of the anæsthesia of pain, and of heat and cold. The distribution of the analgesia and the thermo-anæsthesia is most cơmmonly hemiplegic, limited to one-half of the body, and usually affecting only one of the upper limbs and the adjacent portion of the thorax. That is what one finds in classical cases like that reported by Jackson and Galloway, ${ }^{8}$ 
which I had the privilege of seeing in the London Hospital. Sometimes both upper limbs with adjacent portions of the thorax in the form of a "vest" are affected, but it is distinctly exceptional to have the sensory disturbance generalised over the whole body, though such cases have been reported. ${ }^{\circ}$

1 Morgagni : Adversar. Anatom., vi. 2 Starr : International Journ. Med. Sciences, 1888 , xcv, p. 456 . 3 Bruhl : Contribution d l'Etude de la Syringomyelie, Paris, r8go. New sydenham Society's Translation, London, 1897, p. ro4. This is an excellent monograph, with good bibliography. 4 Bruhl.

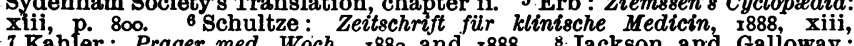
Lancet, $802, i, p, 408$ etc 9 Bruhl. Sydenham Society's Translation, p. ro8.

\section{THE DIAgNosis DURING LIFE OF RETINAL AND LABYRINTHINE HAMORRHAGES IN A CASE OF SPLENIC LEUK AMIA.}

By JAMES FINLAYSON, M.D.

Physician to the Glasgow Western Infirmary and the Royal Hospital for Sick Children, etc.

A CASE of leukæmia which was studied in the Western Infirmary some ten years ago has not yet been reported, but certain points in the diagnosis made me resolve to publish it some time.

The patient was a married woman, aged 29 , with five children ; she was affected with splenic leukæmia, the spleen being enormously enlarged, without any glandular affections recognisable during life. Her fifth child was born in January, 1887 , and her attention was directed to a lump in her left side three months later. In August, 1887, she was admitted to the Glasgow Royal Infirmary, where the lump referred to was identified as a large spleen, and the blood was found to be highly leukæmic-nearly one white to three red corpuscles. No hæmorrhages were found in the retina at that time. After trying a change to her native place-Islay-she was admitted to the Glasgow Western Infirmary on June 14th, 1889. The condition of the spleen was much the same as reported in the Royal Infirmary notes, but it was apparently larger, and the strength and condition generally had deteriorated; slight codema of the feet was present on admission, but it passed off with rest in bed. The blood showed in 1889 very much the same proportion of red to white corpuscles as in 1887 ; we found $1,190,000$ white and $2,080,000$ red corpusles in the cubic millimetre. This was shortly before death. The white corpuscles were mostly of the ordinary size, but about one-fourth of them were larger and more granular, with fatty contents. In 1887 the Royal Infirmary notes indicated the same diversity in size of the white corpuscles.

A month before admission to the Western Infirmary vomiting was troublesome for three weeks, but she seemed to have had no bleedings from the stomach or bowels (except slightly from piles when the bowels were costive), and no epistaxis.

After admission to the Western Infirmary the œedema disappeared, but the bowels became very loose, and this resisted treatment. A small swelling at the left frontal region suppurated and burst; this became erysipelatous, and the redness spread. This was associated with only slight pyrexia (100 to I00.4 F.), but it hastened her death, which occurred on July Igth, I889, fully a month after admission.

The greatest point of interest was the implication of the eyes and the internal ears in a case of leukæmia; the possibility of recognising this during life, as due to hæmorrhages, was a matter of diagnostic interest.

About a month before admission to the Western Infirmary, whilst crossing from Islay in the steamer, she was supposed to have contracted " a cold," and to this she ascribed the deafness and ringing sounds in her ears from which she suffered, as well as the bloodshot appearance in her left eye. While on the steamer she was affected with severe giddiness, when the noises in the ears came on, and she felt sick, although the sea was quite calm at the time. As already stated, there had been an attack of vomiting a week or two before this.

An examination of the left eye showed at once that the blood-shot appearance ascribed to cold was really a conjunctival ecchymosis, and this immediately suggested the probability of thæmorrhages in the fundus; these were readily found on ophthalmoscopic examination. This discovery in its:turn suggested the possibility of hæmorrhages being present in the nervous structures of the internal ear on both sides. The sudden deafness, the noises in the ear, the giddiness, and sickness, all pointed in the direction of a labyrinthine affection. An exploration of the ears was made by Dr. Thomas Barr. Nothing abnormal was found in the external or middle ear, and the Eustachian tubes were easily inflated, but no improvement in the hearing resulted. A watch could not be heard on contact on either side, and the voice was heard only when loudly spoken near to the ears. The tuning-fork was heard longer by air conduction than by bone conduction. The conclusion of Dr. Barr's report on June 17th was: "The suddenness of the onset, the extent of the deafness, the presence of giddiness, and disturbance of head balance at the beginning, as well as the severe tinnitus, point to exudation in the cavities of labyrinth, probably hæmorrhagic in character."

At the examination of the body after death, the eyeballs were removed for examination by Dr. Thomas Reid, and the bones containing the internal structures of the ear were carefully dissected by Dr. Barr. The sections made of the retina displayed the hæmorrhages beautifully, and a microphotograph showed a striking abundance of leucocytes in the blood vessels. The examination of the internal ear showed hæmorrhages in the vestibule and the first turn of the cochlea, not at all in the middle ear.

Amongst other features of interest in the post-mortem examination may be mentioned the size of the spleen, 14 by 8 inches, and the weight, $6 \mathrm{lbs} .4 \frac{1}{2}$ ozs. It presented on section large, yellowish, firm patches of wedge-like shape, suggestive of infarctions, but on microscopic examination no indication was found of this having actually occurred. Some general enlargement of the mesenteric and retroperitoneal lymphatic glands was noted, and similar glands were seen in the neck. The omentum presented numerous, small, pearly nodules. Minute submucous hæmorrhages were seen in the colon with some injection of the vessels. The brain presented nothing specially abnormal, but the veins showed a considerable amount of greenish yellow clot. The heart contained greenish, opaque, fibrinous material, with a grumous fluid residue.

\section{BIBLIOGRAPHY.}

As regards the literature of the subject, the most important contribution is by Gradenigo, in 1886 , who gives a summary of the cases up till thä date. A case by Steinbruegge, in 1887 , presents some resemblance to my case, inasmuch as both the eyes and the ears were affected. From the reports of cases it would seem that in leukæmia there may be hæmorrhagic lesions both in the middle and inner ear, and that these may coexist with hæmorrhage elsewhere. (Something of the same kind has been observed in pernicious anæmia. See Archiv für Ohrenheilkunde, Bd ${ }^{2}$. 23r.)-Politzer, A. Pathologisch-anatomische Veränderungen im Babser in Basel, September Laby A rchiv für Ohrenheilkeunde, Bd. xxii, S. 1oo-Blau, L. Ueber Erkran1884. Archiv fur Ohrenhellu de, Bd. Xxämie Zeitschr. f. klin. Med. Bd. X Hoftracted in Archiv für Ohrenheilkunde. 1886. Bd. xxiii

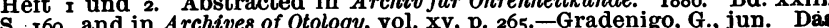
S. 169, and in Archives of Otology, vol. Xv, p. 265. - Gradenigo, G., jun. Geh6. 1886. Ba. X. 242.- Steinbruegge, $\mathrm{H}$. Labyrinvii p. 59. Zeitschrift

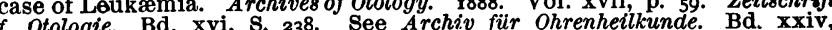
f. tologie. Bd. Xvi, S. 238 . See Archiv fur Ohrenheilkunde. Bd. Xxiv, S. 209. 1887.-Gelle. Leukocythamie mit Taubheit und Faciallahmung beginnend. (Revue Mens. de Laryng ${ }^{1887 .}$ No. $^{12}$ ). See Archiv fur

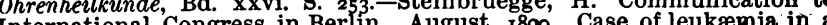
International Congress in Berln. August, r8\%. Case of leukæmia in a girl of 14 years, with hæmorrhages in the middle ear and in labyrinth. Archiv für Ohrenheilkunde. Bd. Xxxi, S. 23x.-Wagenhäuser. Labyrinth 1892. Bd. Xxxiv, S. 219 .

\section{THE ARTHROPATHIC DYSTROPHIES。}

By T. ALDOUS CLINCH, M.D.EDIN., Pathologist to the Durham County Asylum.

\section{Definition of Terms.}

IT is a well-known fact that injuries of joints, often by, no means of a severe character, leave behind them. weakness which not uncommonly lasts for the rest of the sufferer's life. In some cases the weakness and atrophy of the limbs is $\mathbf{8 0}$ marked that special attention has been paid to them, and they were named cases of arthropathic amyotrophy (Charcot).

This name, however; is too limited, for changes occur in 